\title{
Functional movement modeling for robot-assisted upper limb rehabilitation: the case of a simulated reduced-freedom anthropomorphic manipulator
}

\author{
Fernando Gonçalves Abadia, Paulo Roberto Pereira Santiago, Marco Antônio Assfalk de Oliveira, \\ Marcus Fraga Vieira*
}

\begin{abstract}
This paper presents the results of an on-going investigation into the use of an anthropomorphic robotic manipulator with three degrees of freedom (two DOF shoulder joint and one DOF elbow joint) for rehabilitation of a human upper arm. The reduction to three DOF for this manipulator allows for a simpler project, leading to a lower cost of production and maintenance: important factors for its intended wide-spread use in financially restricted areas, e.g., the state of Goiás, Brazil. The project focuses on determining the variations observed for a class of trajectories known as functional movements. These functional movements are trajectories realized when a limb is used for a given function, e.g., combing the hair. In this present paper we use three functional movements: hair combing, bringing a cup to one's mouth and a waving movement. We describe how these functional movements are acquired from test subjects and compared in computer simulations to the equivalent functional movements of our proposed reduced-order anthropomorphic manipulator. Our research indicates that the errors incurred in using a reduced-order shoulder joint are well within the observed variation in the functional movements of human subjects, when compared among different subjects and also between similar functional movements of any one given human subject. Despite the limitations, the proposed manipulator would be viable for rehabilitation of patients in early phases of a stroke, at lower cost of production.
\end{abstract}

Keywords Functional movements, Robot-assisted rehabilitation, Anthropomorphic manipulator.

\section{Modelagem de movimentos funcionais para reabilitação de membros superiores assistida por robô: caso de um manipulador antropomórfico simulado com reduzidos graus de liberdade}

Resumo Este trabalho descreve os resultados de uma investigação do uso de um manipulador robótico antropomórfico de três graus de liberdade (dois GDL na articulação do ombro e um GDL na articulação do cotovelo) na reabilitação do membro superior humano. A redução feita para três graus de liberdade deste manipulador permite a elaboração de um projeto mais simples, levando a custo de produção e de manutenção reduzidos, fatores importantes tendo em vista que se pretende o seu uso em larga escala em áreas de baixa renda, como o estado de Goiás, Brasil, por exemplo. O projeto teve como principal objetivo determinar as variações observadas em uma classe de trajetórias conhecidas como movimentos funcionais. Estes movimentos funcionais são trajetórias percorridas pelo membro quando em uso em uma determinada ação, por exemplo, pentear o cabelo. Neste trabalho, foram utilizados três movimentos funcionais: pentear o cabelo, trazer um copo à boca e o movimento de acenar. Foi descrito como esses movimentos funcionais foram capturados de voluntários e comparados a simulações em computador de movimentos funcionais equivalentes do manipulador robótico antropomórfico proposto. Essa pesquisa indica que as limitações advindas do uso de uma articulação do ombro com redução de um grau de liberdade estão próximas das variações observadas em movimentos funcionais humanos, quando comparados entre diferentes individuos e também entre movimentos funcionais semelhantes de um dado indivíduo. A despeito dessa limitação, o manipulador proposto seria viável na reabilitação de pacientes durante a fase inicial de um acidente vascular encefálico, a um baixo custo de produção.

Palavras-chave Movimento funcional, Reabilitação assistida por robô, Manipulador antropomórfico. 


\section{Introduction}

The use of robotic technology in medicine is increasing considerably nowadays, including in the rehabilitation of patients who have suffered brain vascular injuries and have lost all or part of their voluntary day-to-day movements.

The integration of people affected by these injuries in modern society is a major problem, since they face difficulties in performing simple tasks (functional movements), such as hair combing and grasping or lifting objects. Intensive therapy sessions consisting of repetitions of voluntary movements are necessary for their rehabilitation, and promote a remapping of the motor cortex neural circuitry (Kawahira et al., 2004; Reinkensmeyer and Housman, 2007).

During rehabilitation therapy, patients with some disabilities or with partial voluntary movements (due to an injury), require the assistance of occupational therapists and physiotherapists, who move the patients affected members in various series of repetitive exercises. According to some authors, there is substantial evidence that repetitive movements can help in the rehabilitation of such patients (Riener, 2007).

Gentile in Carr and Shepherd (2006) describes the following stages of motor learning: first occurs the idea of the movement, and then the ability to adapt the movement pattern to environmental requirements is developed. In the early stages, the patient learns to pay attention to critical features of the action and is actively engaged in practicing. Thus, the patient may be seen as an apprentice and the therapy requires the creation of attractive environments and methods that encourage the learning of the desired skills.

The goal of robot-assisted rehabilitation is to decrease the patient's physical dependence on the therapist during these exercises, replacing the therapist's physical assistance for a robotic device, under the therapist's supervision and control.

The objective of this research is to determine and to analyze the appropriate modeling of kinematics and other parameters for an anthropomorphic robot arm with few degrees of freedom, which best approximate the functional movements to be relearned by the rehabilitation patients. Thus, we are seeking lower costs and determining the feasibility of such a rehabilitation robot.

In order to achieve these goals, the following functional movements were investigated: the hair combing (FM1), bringing a cup to one's mouth (FM2) and waving (FM3).

\section{Materials and Methods}

\section{Initial remarks}

All procedures received the approval by Ethics Council for Research on Human Beings of Federal University of Goiás - protocol number 141/09.

Three selected volunteers, range 21-25 years, all Federal University of Goiás students, participated in the study (volunteers A, B and C). The volunteers presented no history of injury or surgery (orthopedic assessment performed by a physiotherapist), along with no complaints of joint pain during activities of daily living.

The laboratory research was initially developed with data collected from the three volunteers, executing the three upper limb functional movements. The volunteers repeated the movements three times. The resulting data forms the basis for comparison with the simulated robotic equivalent movements.

\section{Data collection and analysis}

Prior to the video recordings of the functional movements of the human arm, the volunteers performed the proposed tasks several times in order to be familiarized with them. Following this acquainting period, eight reflective markers were positioned in selected anatomical points (Figure 1c).

The reflective markers were made with small Styrofoam balls covered with reflective tape and fixed by means of adhesive double-sided tape on the skin (Figure 1a). To facilitate the contrast and accuracy of the markers and improve the visualization of anatomical points in the movement, the volunteers used black clothes with elastic fabric cut in the places where the markers were fixed, so that the markers were fixed on the skin minimizing the vibration problem and avoiding errors in marking and scanning (Figure 1b).

The glenohumeral joint was represented by the marker fixed in shoulder (GH), while the elbow joint by the midpoint between the lateral (EpL) and medial epicondyle (EpM) of humerus. The wrist joint is the midpoint between the radial (RS) and the ulnar (US) styloid process (Wu et al., 2005). The upper arm is represented by the line connecting the $\mathrm{GH}$ to the midpoints of the epicondyles, while the forearm is represented by the line connecting both midpoints mentioned above as showed in Figure 1d.

The Incisura Jugularis (IJ), Processus Xiphoideus (PX) and Acromioclavicular (AC) points were used to calculate angles: Abduction/Adduction and Flexion/ Extension of the shoulder.

The trials were recorded by four digital cameras (Panasonic NV-GS320 ${ }^{\circledR}$ ) operating at the acquisition 


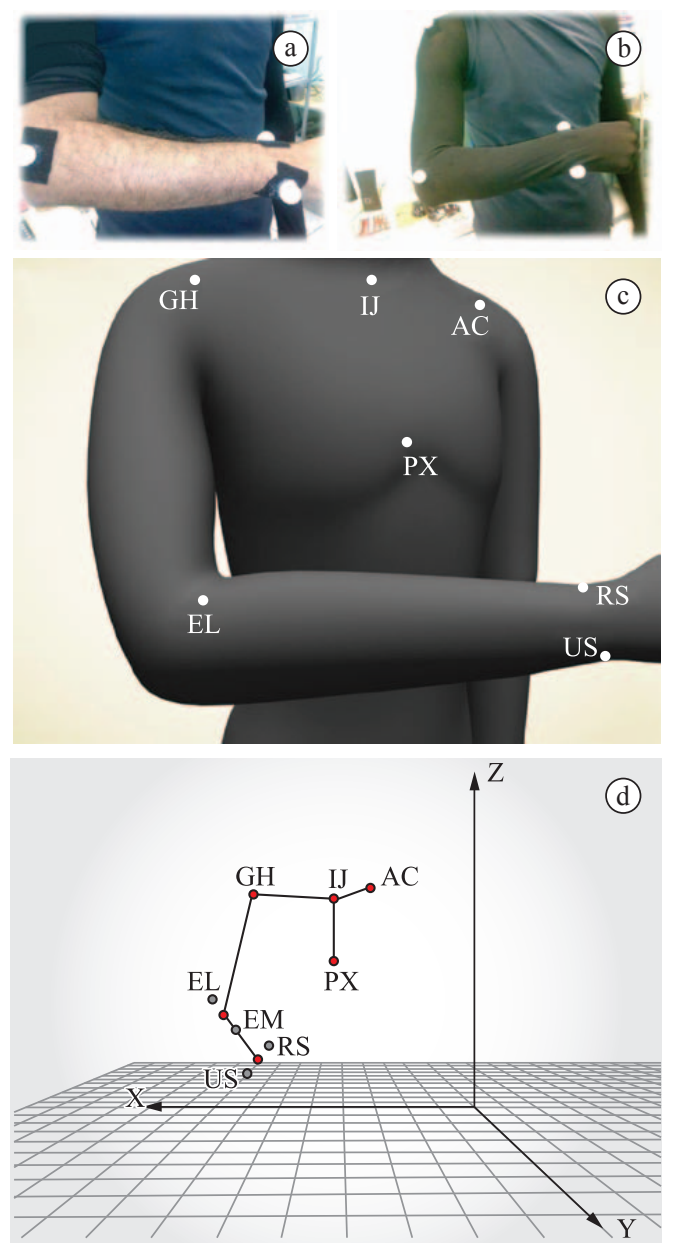

Figure 1. a) - Reflective markers on the skin. b) Black clothes with elastic fabric. c) Anatomic tracking points on subject's arm. d) Graphical representation of the anatomical points and lines used to capture the volunteer's functional movements. Shoulder - Glen Humeral (GH), Incisura Jugularis (IJ), Processus Xiphoideus (PX), Acromioclavicular (AC), Lateral Epicondyle (EpL), Medial Epicondyle (EpM), Radial (RS) and Ulnar (US) Styloid Process.

frequency of $60 \mathrm{~Hz}$. The cameras were positioned such as they could capture all the landmarks and they were located as showed in Figure $2 b$.

For the calibration procedure an object with $1.80 \mathrm{~m} \times 0.80 \mathrm{~m} \times 1.00 \mathrm{~m}$ dimension was filmed in the area where the volunteers performed the proposed tasks (red parallelepiped in Figure 2a). This object, composed by four strands of nylon attached to the ceiling, had 12 control points with known absolute positions (letters in Figure 2a). The global reference system, fixed in relation to laboratory, was then defined from this calibration object using KWON3D software in 3.1 version, where the $Z$ axis was defined in the vertical position oriented upwards, the $Y$ axis was oriented in the anterior-posterior direction of

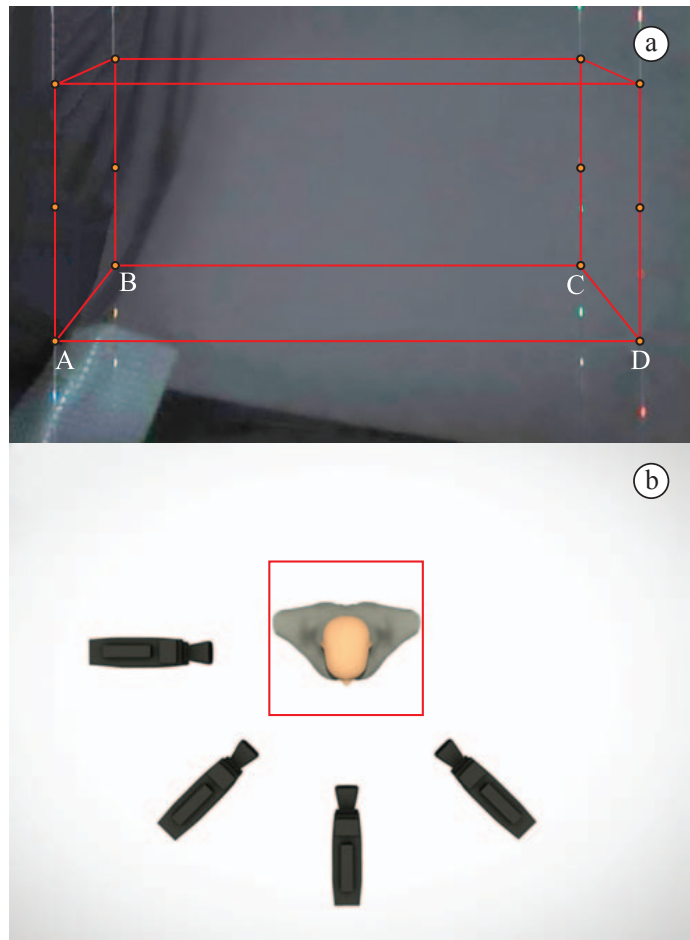

Figure 2. Movement Capture Calibration: a) calibration volume shown with reference strands and reflective control points. The letters indicate some control points $(\mathrm{cm}): \mathrm{A}=[125.9,100,30]$, $\mathrm{B}=[125.4,0,30], \mathrm{C}=[0,0,30]$ and $\mathrm{D}=[0,100.2,30]$. b) Subject and camera positions.

the volunteer, and the $X$ axis was defined as the cross product of the vectors $Y$ and $Z$ in the mediolateral direction (Figure 1d and 2a). The calculated calibration error was $0.1 \mathrm{~cm}$, verified using a specific test (Ehara et al., 1996).

The trunk reference system was positioned on $\mathrm{GH}$ marker (shoulder) parallel to global reference system.

The cameras were synchronized by a beep frame. The angular position and orientation data were extracted automatically and manually using KWON3D software, which utilizes the direct linear transformation (DLT) method for 3D representations (Abdel-Aziz and Karara, 1971). The data were smoothed by a low-pass, fourth order Butterworth filter with a cutoff frequency of $5 \mathrm{~Hz}$, according to the residual analysis (Winter, 2009).

This $3 \mathrm{D}$ reconstruction provided us with the specific positions of each anatomical point in space, in the $X, Y$ and $Z$ axes, working with two types of variables: independent, related to the position and orientation of joints, and the dependent variables: the angles, speed and acceleration. These variables were used to generate calculated parameters, used in the analysis of data for the proposed kinematic study. 


\section{Kinematic Problem Statement}

\section{Robotic simulation}

In this project, to address the direct kinematics, a reduced degree of freedom simulated anthropomorphic arm was created using the Matlab software (Abdullah et al., 2007; Corke, 2008; Epokh, 2009), as shown in Figure 3a. The usual five degrees were reduced to three degrees by fixing one degree at the shoulder joint and one degree at the elbow joint, decreasing those joints's complexity and, accordingly, its cost.

The resulted kinematic equation is derived by the setup of the robotic arm which is composed by two successive links. Therefore, it is necessary to know all the parameters involved in each link of the robot. The relative position and orientation of these two successive links may be represented by two parameters given by the Denavit-Hartenberg (DH) parameters.

To solve the constraints generated by the kinematic chain of the robot, we must have a mathematical description of the spatial transformations between each joint. These general formulations were based on DH notation (Craig, 1989), whose parameters are shown in the Table 1.

\section{Inverse kinematics}

The direct kinematics determines the position and the orientation of the end effector from joint angles, whereas the inverse kinematics determines the angles of the joints from the position and orientation of the same end effector.

The inverse kinematics cannot be obtained through simple matrices multiplications. However, for this robotic manipulator, where the axes intersect at a point, it is possible to decouple the inverse kinematics problem into two simpler problems: inverse position kinematics and inverse orientation kinematics (Spong et al., 2006).

Considering the manipulator shoulder shown in Figure 3c, we have $X, Y$ and $Z$ coordinates points of the elbow (EL) and wrist (WR). The elbow coordinates (EL dot) was projected onto the $Y Z$ plane of the trunk reference system and from this projection we generate the opposite and adjacent sides. Then, using the arctangent function we can calculate angle $\theta_{1}$ (flexion and extension at shoulder):

$$
\theta_{1}=\tan ^{-1}\left(\frac{Z_{\text {elbow }}}{Y_{\text {elbow }}}\right)
$$

To calculate the angle $\theta_{2}$, a vector $L_{1}$, representing the arm length, was defined with its origin at the shoulder (GH dot) and its end at the elbow (EL dot). The elbow coordinates (EL dot) was used to generate
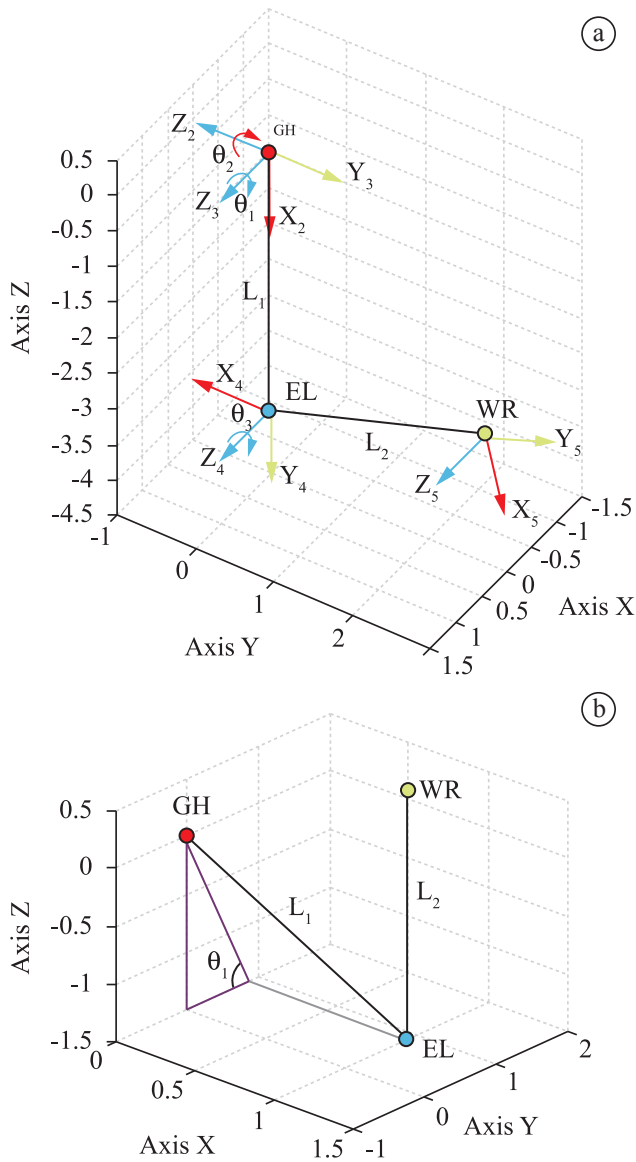

(c)

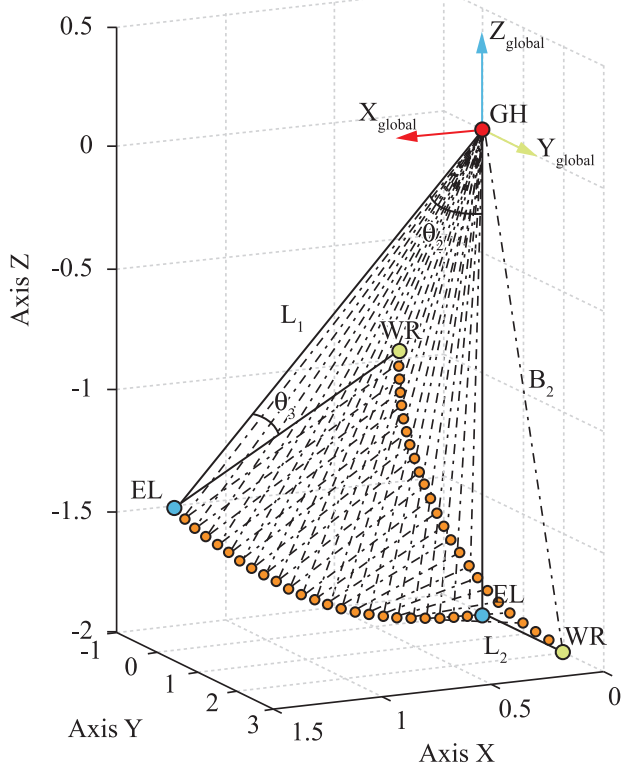

Figure 3. a) MatLab simulation of FM2 movement obtained with the reduced-DOF anthropomorphic arm. $\mathrm{L}_{1}$-upperarm, $\mathrm{L}_{2}$-forearm; b) Triangle projected on the $\mathrm{YZ}$ plane of the $\mathrm{L}_{1}$ segment, from which angle $\theta_{1}$ is calculated; c) MatLab simulation of the inverse kinematic in its reference configuration (see text). Shoulder (GH), Elbow (EL), Wrist (WR). 
the vector $X_{\text {elbow }}$ (origin at elbow and perpendicular at the $Z Y$ plane) which is used to calculate the angle representing adduction and abduction at a shoulder on the trigonometry rule:

$$
\theta_{2}=\sin ^{-1}\left(\frac{X_{\text {elbow }}}{L_{1}}\right)
$$

Finally, to calculate the final angle (flexion and extension of the elbow) was defined a vector $\mathrm{B}_{2}$ between the GH (origin) and WR point (wrist) and was applied the law of cosines:

$$
\theta_{3}=\cos ^{-1}\left(\frac{B_{2}-\left(L_{1}^{2}+L_{2}^{2}\right)}{2 \cdot L_{1} \cdot L_{2}}\right)
$$

For each angle we could find two solutions, meaning that the manipulator can access eight different specific locations. However, some of these solutions are not desirable due to restrictions of movement generated within the own project.

The kinematic chain was calculated with the values of the angles $\theta_{1}, \theta_{2}$, and $\theta_{3}$ locked in zero. The inverse kinematics was calculated with the direct kinematic answer. The resulting error is shown in Table 2.

As can be seen, the resulting error is of the order of $10^{-13}$ which is negligible.

\section{Results}

By applying the joint data obtained experimentally to the direct kinematics matrices corresponding to the DH notations described above, simulated positions were obtained. A graphical comparison of simulation results with the experimental trajectories is shown in Figure 4, 5 and 6 for FM1, FM2 and FM3 respectively.

Table 1. Adopted kinematic model DH parameters.

\begin{tabular}{ccccc}
\hline Link (i) & $\mathbf{a}_{\mathbf{i}}(\mathbf{m})$ & $\alpha_{\mathbf{i}}(\mathbf{r a d})$ & $\mathbf{d}_{\mathbf{i}}(\mathbf{m})$ & $\theta_{\mathbf{i}}(\mathbf{r a d})$ \\
\hline 1 & 0 & $\pi / 2$ & 0 & $\pi / 2$ \\
2 & 0 & $\pi / 2$ & 0 & $\theta_{1}$ \\
3 & 0 & $-\pi / 2$ & 0 & $\theta_{2}$ \\
4 & $\mathrm{~L}_{1}$ & 0 & 0 & $-\pi / 2$ \\
5 & $\mathrm{~L}_{2}$ & 0 & 0 & $\theta_{3}$ \\
\hline
\end{tabular}

Table 2. Forward and inverse kinematics with the respective error.

\begin{tabular}{cccc}
\hline \multirow{2}{*}{$\begin{array}{c}\text { Angles } \\
(\text { rad })\end{array}$} & \multicolumn{3}{c}{ Kinematic (value $\times$ 1.0e-013) } \\
\cline { 2 - 4 } & 0 & Inverse & Error \\
\hline$\theta_{1}$ & 0 & 0.0711 & -0.0711 \\
$\theta_{2}$ & 0 & -0.2842 & 0 \\
$\theta_{3}$ & & & 0.2842 \\
\hline
\end{tabular}
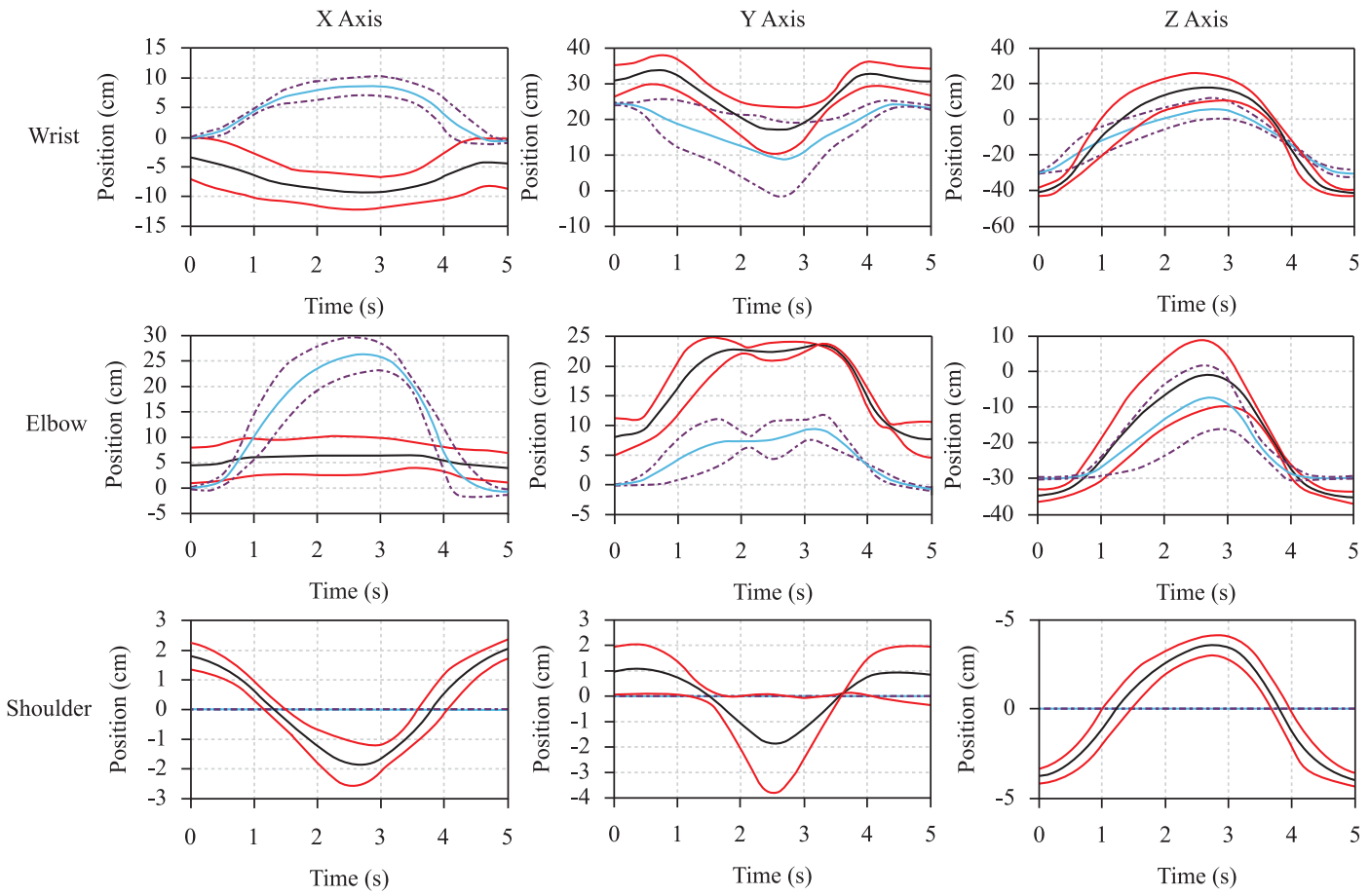

$$
\begin{array}{|lllll|}
\hline & \text { Mean } & - & \text { SD } & - \\
\hline
\end{array}
$$

Figure 4. Mean trajectories (shown with standard deviation error) of the simulated positions (blue and purple) and evaluated positions (black and red) along $\mathrm{X}, \mathrm{Y}$ and $\mathrm{Z}$ axes for the FM1 movement. 

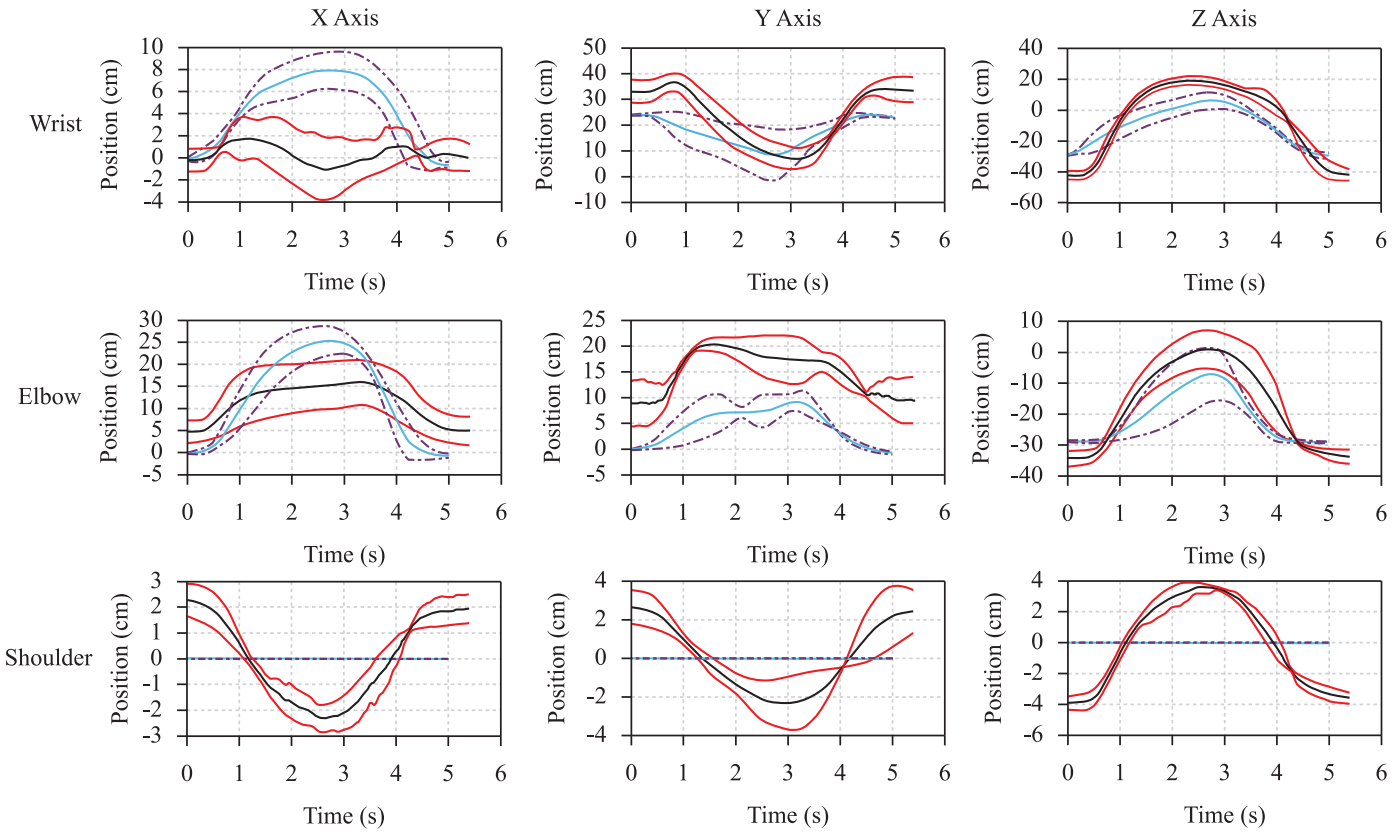

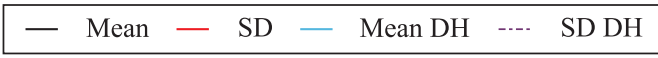

Figure 5. Mean trajectories (shown with standard deviation error) of the simulated positions (blue and purple) and evaluated positions (black and red) along $\mathrm{X}, \mathrm{Y}$ and $\mathrm{Z}$ axes for the FM2 movement.
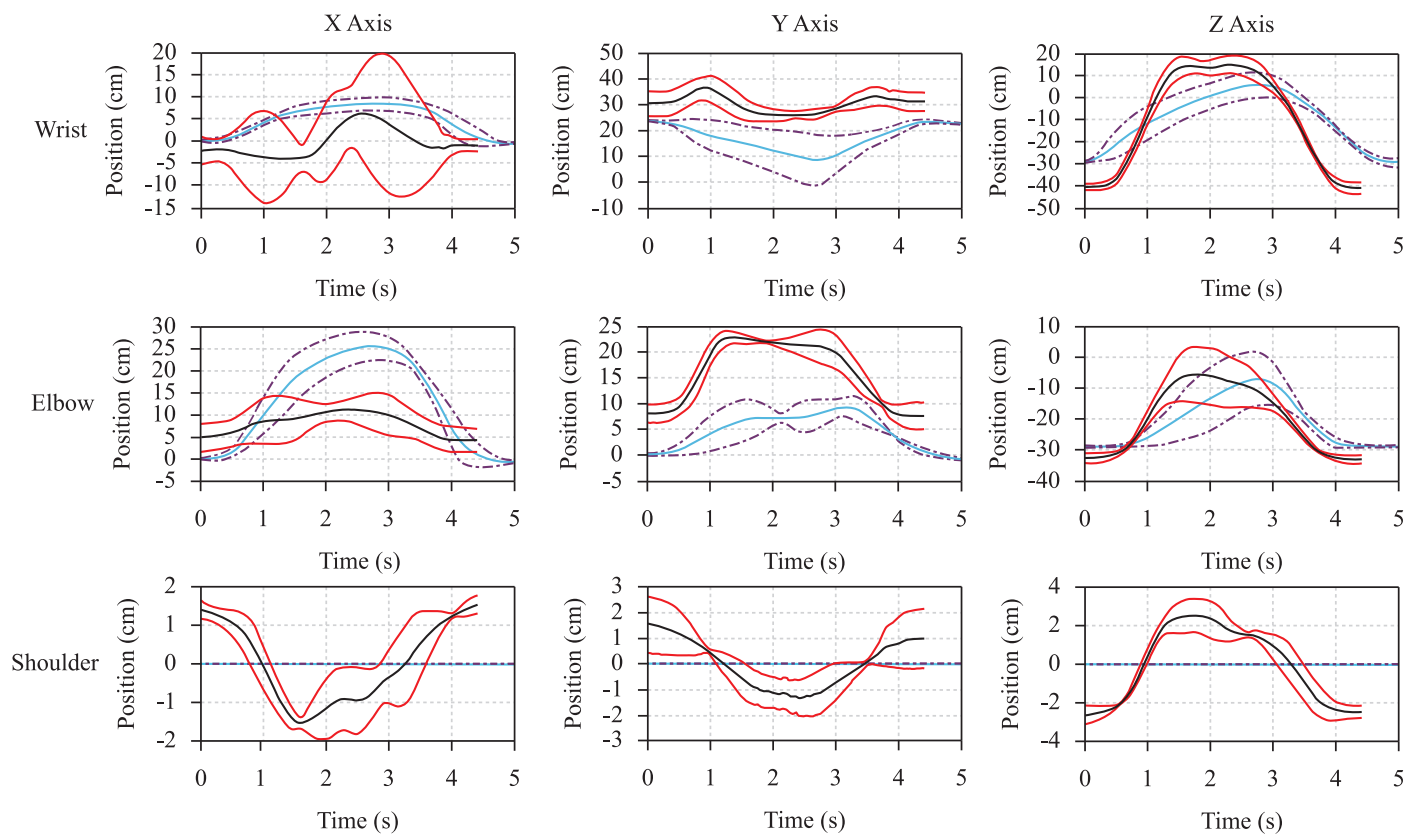

$$
\begin{array}{lllll|}
\hline & \text { Mean }-\mathrm{SD} & - & \mathrm{M} & \mathrm{M} \\
\hline
\end{array}
$$

Figure 6. Mean trajectories (shown with standard deviation error) of the simulated positions (blue and purple) and evaluated positions (black and red) along $\mathrm{X}, \mathrm{Y}$ and $\mathrm{Z}$ axes for the FM3 movement. 
These plots show the overall mean and the standard deviation (SD) for each movement, as performed by the three volunteers.

\section{Discussion}

At the current research phase, the simulated shoulder does not exhibit translation movement, only flexion and extension and adduction and abduction, decreasing the cost of a future implementation. However, as expected, this configuration generates a positional error, which is not critical and does not invalidate the approach, because the human shoulder movements in this case are small, being compensated by other joints in the simulated movement. There is on average a difference of $2.2 \mathrm{~cm}$ between the real and the simulated shoulder joint movement for all axes, and a corresponding error of less than $8.5 \%$ for high amplitude (complete movement) and less than $1.5 \%$ for low amplitude of movement.

There is a satisfactory similarity when comparing simulated positions and evaluated positions along $Y$ and $Z$ axis. However, as expected, the positions along $X$ axis exhibited a poor matching. The poor matching on the $X$ axis is possibly due to the lack of one degree of freedom on the shoulder of the simulated robotic manipulator (lateral and medial rotation), which was not implemented because of project cost restrictions as explained above.

The rightward shift seen in the $X$ axis plots can be attributed to a change in the elbow trajectory (compensation), when the simulated robotic manipulator attempts to perform the movement with three degrees of freedom in the simulations (two on the shoulder and one on the elbow).

At first look, the separate $\mathrm{X}, \mathrm{Y}$ and $\mathrm{Z}$ axes comparison between the proposed reduced-order arm and the experimental subjects' movements indicate similarities (along $\mathrm{Y}$ and $\mathrm{Z}$ axes) and some marked differences (along $\mathrm{X}$ axis). However, the resultant movement of the end effector (hand), i.e. the trajectory of the hand, is quite similar for both realizations, falling into the ordinary error range seen among movements realized by different human subjects.

\section{Conclusions}

The specific anthropomorphic robotic manipulator investigated has shown reasonable approximations to the three functional movements considered, despite the restrictions entailed by its reduced DOF configuration (two DOF shoulder joint and one DOF elbow joint), but the movements obtained using a simulation program cannot be considered fully functional, since they deviate from the human reference movements along the elbow $X$ axis.
As a solution for the changing of the elbow trajectory due to the lack of lateral and medial rotation of the shoulder, the absent degree of freedom should be added improving the performance of the anthropomorphic arm and, therefore, the movement could be considered more functional, but with increasing costs.

However, at this stage of modeling, the reduced DOF robot can still be useful as it can be applied in the early stages after a stroke, when the patients exhibit low-amplitude movements. Early initiation of active movements by means of repetitive training has proved to be positive in guaranteeing a better level of motor capability recovery during the early stages after a stroke (Butefisch et al., 1995). For low amplitude movements the mismatch between real and simulated trajectories is less than $1.5 \%$, which can be considered acceptable. Thus, despite the limitations, the implementation of this low cost robot is attractive.

Compared with conventional treatment, patients who received robot-assisted therapy for the proximal upper limb, even in addition to conventional therapy, showed greater improvements in functional capabilities (Kwakkel et al., 2008; Lum et al., 2002; Masiero et al., 2007). In this way, this study contributes in determining the functional typical movements of reference, which would be adjusted by the therapists to the therapeutic needs of each patient.

These functional movements could also be inserted into a treatment program for medium and long term, in which the rehabilitation therapy is gradually moving from a passive-active (patient and handler, respectively) to an active-reactive process, where the patient's muscle strength is also trained with the robotic arm acting as a variable load.

\section{Acknowledgement}

The authors are grateful to CAPES, CNPq, FUNAPE and FAPEG for supporting this research and to D. Almeida for the assistance with the figures.

\section{References}

Abdullah HA, Tarry C, Datta R, Mittal GS, Abderrahim M. Dynamic biomechanical model for assessing and monitoring robot-assisted upper-limb therapy. Journal of Rehabilitation Research \& Development. 2007; 44(1):43-62. http://dx.doi. org/10.1682/JRRD.2006.03.0025

Butefisch C, Hummelsheim P, Densler P, Mauritz K. Repetitive training of isolated movements improves the outcome of motor rehabilitation of the centrally paretic hand. Journal of Neurological Sciences. 1995; 130(1):59-68. http://dx.doi.org/10.1016/0022-510X(95)00003-K 
Carr JH, Shepherd R. The changing face of neurological rehabilitation. Revista Brasileira de Fisioterapia. 2006; 10(2):147-56. http://dx.doi.org/10.1590/ S1413-35552006000200003

Corke PI. Robotics Toolbox for Matlab. Release 8. 2008.

Craig JJ. Introduction to Robotics: Mechanicals and Controls. 2th ed. Canada: Addison-Wesley Publishing Company; 1989.

Ehara Y, Fujimoto H, Mochimaru M, Tanaka S, Yamamoto S. Comparison of the performance of 3D camera system II. Gait \& Posture. 1997; 5(3):251-5. http://dx.doi.org/10.1016/ S0966-6362(96)01093-4

Epokh. Robotic Toolbox [Internet]. 2009 May [cited 2009 May 10]. Available from: http:/www.epokh.org/drupy

Kawahira K, Shimodozono M, Ogata A, Tanaka N. Addition of intensive repetition of facilitation exercise to multidisciplinary rehabilitation promotes motor functional recovery of the hemiplegic lower limb. Journal of Rehabilitation Medicine. 2004; 36(4):159-64. PMid:15370731. http://dx.doi.org/10.1080/16501970410029753

Kwakkel G, Kollen BJ, Krebs HI. Effects of robotassisted therapy on upper limb recovery after stroke: a systematic review. Neurorehabilitation and Neural Repair. 2008; 22(2):111-21. PMid:17876068. PMCid:2730506. http://dx.doi.org/10.1177/1545968307305457

Lum PS, Burgar CG, Shor PC, Majmundar M, Van der Loss M. Robot-assisted movement training compared with conventional therapy techniques for the rehabilitation of upper-limb motor function after stroke. Archives of Physical Medicine and Rehabilitation. 2002; 83:952-9. PMid:12098155. http://dx.doi.org/10.1053/apmr.2001.33101

Masiero S, Celia A, Rosati G, Armani M. Robotic-assisted rehabilitation of the upper limb after acute stroke. Archives of Physical Medicine and Rehabilitation. 2007; 88:142-9. PMid:17270510. http://dx.doi.org/10.1016/j. apmr.2006.10.032

Reinkensmeyer DJ, Housman SJ. If I can't do it once, why do it a hundred times?: Connecting volition to movement success in a virtual environment motivates people to exercise the arm after stroke. IEEE Virtual Rehabilitation. 2007. p. 44-8. http://dx.doi.org/ICVR.2007.4362128

Riener R. Patient-Interactive Robots for Arm and Gait Rehabilitation. Berlin: Technical Aids in Rehabilitation; 2007.

Spong MW, Hutchinson S, Vidyasagar M. Robot Modeling and Control. United States of America: John Wiley \& Sons; 2006.

Winter DA. Biomechanics and Motor Control of Human Movement. 4th ed. United States of America: John Wiley \& Sons; 2009. http://dx.doi.org/10.1002/9780470549148

Wu G, Van de Helm FCT, Veeger HEJ, Makhsous M, Van Roy P, Anglin C, Nagels J, Karduna RK, McQuade K, Wang X, Werner FW, Buchholz B. ISB recommendation on definitions of joint coordinate systems of various joints for the reporting of human joint motion - Part II: shoulder, elbow, wrist and hand. Journal of Biomechanics. 2005; 38(5):981-92. PMid:15844264. http://dx.doi.org/10.1016/j. jbiomech.2004.05.042

\section{Authors}

\section{Fernando Gonçalves Abadia}

Post-graduate Program of Electrical and Computer Engineering, Federal University of Goiás - UFG, Goiânia, Go, Brazil

Paulo Roberto Pereira Santiago

School of Physical Education and Sport of Ribeirão Preto, University of São Paulo - USP, Ribeirão Preto, SP, Brazil

\section{Marco Antônio Assfalk de Oliveira}

School of Electrical and Computer Engineering, Federal University of Goiás - UFG, Goiânia, Go, Brazil

\section{Marcus Fraga Vieira}

Laboratory for Bioengineering and Biomechanics, Federal University of Goiás - UFG,

Mail Box 131, Zip Code 74001-940, Goiânia, Go, Brazil 